\title{
Support scattering effects on low-gain satellite antenna pattern measurements
}

\section{Appel-Hansen, Jørgen}

\section{Published in:}

I E E E Transactions on Antennas and Propagation

Publication date:

1973

Document Version

Publisher's PDF, also known as Version of record

Link back to DTU Orbit

Citation (APA):

Appel-Hansen, J. (1973). Support scattering effects on low-gain satellite antenna pattern measurements. I E E E Transactions on Antennas and Propagation, 21(3), 370-371.

\section{General rights}

Copyright and moral rights for the publications made accessible in the public portal are retained by the authors and/or other copyright owners and it is a condition of accessing publications that users recognise and abide by the legal requirements associated with these rights.

- Users may download and print one copy of any publication from the public portal for the purpose of private study or research.

- You may not further distribute the material or use it for any profit-making activity or commercial gain

- You may freely distribute the URL identifying the publication in the public portal

If you believe that this document breaches copyright please contact us providing details, and we will remove access to the work immediately and investigate your claim 
[13] J. W. Sherman and M. I. Skolnik, "Thinning planar array antennas with ring arrays," 1963 Int. Conv. Rec., pt. I.

[14] $\mathrm{Y}$.T. Lo "A mathematical theory of antenna arrays with randomly spaced elements," IEEE Trans. Antennas Propagat., vol. AP-12, pp. 257-268, May 1964 . [15] B. D. Steinberg, "The peak sidelobe of the phased array having vol. AP-20, pp. 129-136, Már. 1972.

\section{Support Scattering Effects on Low-Gain Satellite Antenna Pattern Measurements}

\section{J. APPEL-HANSEN}

Abstract-The purpose of the present investigation is to determine the difference between the scattering effects from two types of supports on satellite antenna pattern measurements. The difference in scattering effects is estimated by comparing low-gain antenna patterns recorded when using a foam tower and a model tower.

\section{INTRODUCTION}

Usually the scattering effects of antenna supports may be neglected in antenna measurements. For example in the case of measuring the gain of high-gain antennas. However, when low-gain satellite antennas are to be evaluated experimentally, the supports may influence the antenna patterns drastically. Therefore, it is important to have a feeling of the influence of the different supports which may be available at test ranges. Generally, the supports may be divided in to two types, one type which has advantages in handling capability of antennas and another type which has advantages in low scattering effects. It is the purpose of this communication to describe the difference in scattering influence of the two types of supports. It is supposed that the results obtained will give the scientist a better background for seleeting his support and predicting its influence.

The difference between the two types of supports has been investigated by recording antenna patterns of a scale model of the Geos satellite. In Fig. 1, the satellite mounted on top of a simple foam tower made of polystyrene is shown. The foam tower has low scattering effect, but allows only antenna patterns to be recorded in a horizontal plane. In Fig. 2, the satellite attached to the head of a model tower is illustrated. The model tower has a tower mast made of polyester and a dielectric head which permits easy recording of three-dimensional antenna patterns. The tower mast is inclined at an $80^{\circ}$ angle to reduce scattering effects and is offset at the base to permit rotation about the model centerline. The long cylinder made of wood was connected to the satellite body in order to allow the satellite with various antennas and booms to be mounted on the model tower support. In accordance with Figs. 1 and 2, this communication is based on experiments where the satellite antenna system was of the turnstile type and no booms were attached to the satellite. The measurements were earried out at about $670 \mathrm{MHz}$ in a radio frequency chamber. In the satellite a battery powered transmitter was placed. Antenna patterns were recorded with right- and lefthand circular polarized receiving antennas.

\section{Results}

A standard spherical coordinate system with the axis of the satellite cylinder and the $z$-axis coincident was used. Antenna patterns were recorded in several meridian planes. In Fig. 3, some typical patterns are shown. It appears that the patterns recorded with the right-hand polarized receiving antenna has a maximum in the $\theta=0^{\circ}$ direction, whereas the patterns recorded with the left-hand polarized receiving antenna has its maximum in the

Manuscript received July 13, 1972; revised November 2, 1972 The author is with the Laboratory of Electromagnetic Theory, Technical University of Denmark, Lyngby, Denmark.



Fig. 1. Satellite on top of foam tower.

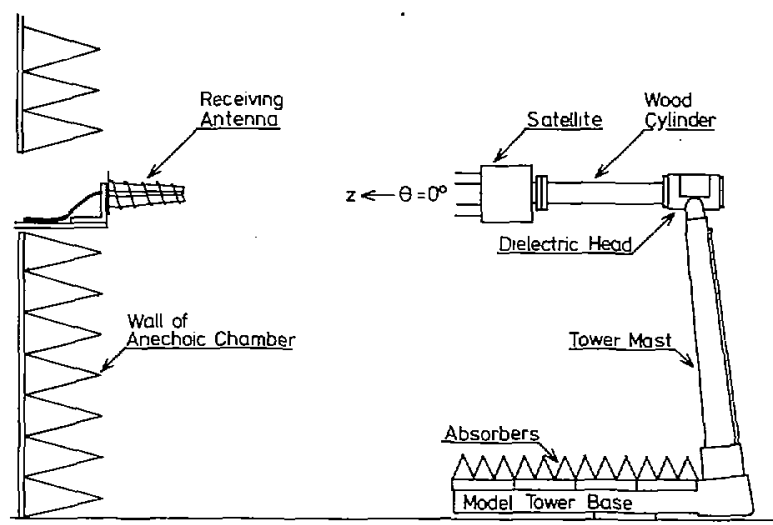

Fig. 2. Satellite mounted on model tower.


Fig. 3. Right- and left-hand polarized patterns.

opposite direction, i.e., in the $\theta=180^{\circ}$ direction. This is mainly due to edge currents on the satellite body generated by the turnstile antenna. From the patterns in Fig. 3 it is possible to make a comparison between patterns recorded when the satellite is mounted on the foam tower and when it is attached to the model tower. It appears that the model tower patterns have variations which are not present in the foam tower patterns. From an analysis of Figs, 1 and 2, which show the mounting of the satellite in the two cases, we conclude that the oscillations in the model tower patterns are due to the dielectric head and mast of the model tower. Since the dielectric head is closest to the satellite, it is supposed that the oscillations are mainly due to the dielectric head. The oscillations in the patterns have the highest frequency at $\theta=90^{\circ}$. This can 
easily be understood by noting that the phase difference $\phi$ between the received electric-field intensities from the satellite and the head is given by the equation

$$
\phi=2 k d \cos \theta
$$

where $k$ is the free-space propagation constant and $d$ is the distance between the satellite and the head. It is seen that the derivative of $\phi$ assumes its maximum value at $\theta=90^{\circ}$, where the satellite and head move fastest relative to the receiving antenna.

A further analysis of all the recorded patterns shows that when we, by an averaging procedure carried out as indicated in Fig. 3, neglect the oscillations in the model tower patterns, the two sets of patterns agree in shape. The difference in the maximum power levels of the patterns is mainly due to different transmitting power levels and different sensitivity of the receiving system during the measurements of the two sets of curves. The time difference between the recording of the two sets of curves was one day, and the oscillator in the satellite had to be retuned. The frequency drif $t$ of the oscillator during the measurements was taken into account. There only was a frequency difference of about 1-2 $\mathrm{MHz}$ between corresponding patterns.

When we neglect the difference in the maximum power level and make the aforementioned averaging, it appears from Fig. 3, that there is only a discrepancy of about $1 \mathrm{~dB}$ between the patterns, for pattern levels above $-\mathbf{1 5} \mathrm{dB}$ relative to the pattern maxima. It is assumed that the discrepancies are mainly due to reflections from the anechoic chamber. For pattern levels below $-\mathbf{1 5} \mathrm{dB}$, the influence of reflections becomes larger. In fact, measurements have shown that the background level of reflections in the anechoic chamber is less than $-23 \mathrm{~dB}$ at the test frequency for the present low gain satellite antenna [1].

In the aforementioned comparison, the oscillations of the model tower pattern could be neglected. This was due to the separation between the dielectric head and the satellite caused by the wooden cylinder. In case of no such separation, it may not be possible to separate the influence of the dielectrie head from the satellite antenna pattern.

\section{Conclusion}

The influence of two different tower supports on low-gain satellite antenna patterns has been investigated. The supports were a foam tower of polystyrene and a model tower with a tower mast of polyester and a dielectric head. For the two types of towers, the major difference between recorded patterns was some oscillations in the model tower patterns which were not present in the foam tower patterns. Analysis showed that these oseillations were mainly due to the dielectric head of the model tower.

\section{ACKNOWLEDGMENT}

The author gratefully acknowledges the interest and support provided by L. G. Sundin and L. M. Ericsson, Sweden.

\section{References}

[1] J. Appel-Hansen, "Reflectivity level and support scattering effects in low gain satellite antenna pattern measurement," Lab. Electromagnetic Theory, Tech. Univ, Denmark, Lyngby, Denmark; $R 111$ Oct. 1972 .

\section{The Performance of Transistor Fed Monopoles in Active Antennas}

\section{A. P. ANDERSON AND M. M. DAWOUD}

Abstract-The performance of radiating elements in the form of monopoles and driven by transistors is examined theoretically and experimentally. A single element comprising a printed monopole

Manuscript received July 14, 1972 ; revised January 5, 1973.

The authors are with the Department of Electronic and Electrical Engineering, University of Sheffield, Sheffield, England. over a ground plane and fed at its terminals by a microwave transistor is shown to have superior frequency characteristics compared to the passive element. Using a two-element array configuration, it is verified that the mutual impedance values are suppressed. The improved individual characteristics of the active elements together with their mutual behavior combine to produce a significantly improved frequency performance of the array. The results presented suggest that the transistorized array principle offers a means both of maintaining directivity of a transmitter, and discriminating against interfering sources by a receiver, over a greater frequency band.

\section{INTRODUCTION}

During recent years, several publications have indicated a growing interest in "active antennas." Although this terminology could include adaptive antennas and phased arrays, the common factor in the class of antennas to which this communication refers is the incorporation of an active device with the structure of a radiating element such that the passive element characteristics are modified or eapable of being controlled. In particular, the use of transistors as the active elements has yielded several improvements in the performance of single radiating elements. A miniature antenna with a transistor connected at an appropriate point along the structure has a lower resonant frequency, higher radiation resistance, and consequently wider bandwidth than the equivalent passive element [1], [2]. A receiving array of active elements, in which a transistor amplifier is mounted directly across each passive radiating element, permits control of the radiation pattern, an improved system noise factor, and increased gain [3].

Another consequence of incorporating transistors with arrays of radiating elements is the suppression of elemental mutual coupling effects in the feed network [4]. Similar ideas have also been proposed for a receiving array using the principle of a buffer amplifier associated with each array element [5] although in this approach, an analysis of the transmitting array was not developed since it appeared to be different. The essence of [4] is that suppression of mutual coupling effects is obtained when the radiating elements operate under substantially open-circuit conditions. Hence the possible advantages apply equally to transmitting and receiving arrays provided that the transistors present a sufficiently high impedance at the terminals of each array element.

Using the impedance parameters of existing microwave transistors, a greater frequeney band is predicted [6] for an array antenna and the possibility of suppressing radiation in unwanted directions also arises.

This communication describes the reality of the predictions given in [4] and [6] and also the preservation of the radiation pattern over a wider frequency band, using as an example a two-element transmitting array of transistor-fed monopoles.

\section{Construction and Performance of Single-Active Elemmat}

\section{A. Design of Radiating Element}

The form of radiating element chosen for this investigation is a monopole one-quarter wavelength long at $1 \mathrm{GHz}$ mounted over a ground plane. A printed-circuit construction is used to facilitate integration with a Hewlett Packard 21 series type 35823E microwave Si planar transistor and the collector biasing network. The emitterbase voltage is applied through a miniature coaxial bias-tee in the feed line. Fig. 1 shows the constructional details of an active element and, for comparison, an equivalent passive element. It was verified experimentally that the characteristics of the printed passive monopole are identical with those of a thin cylindrical monopole and hence the theoretical values of the latter were used for the computed performance.

\section{B. Input Impedance of Single-Active Element}

The impedance presented to the feeding line by a thin cylindrical monopole of height $l$ and radius $R$ over an ideal infinite ground 